\title{
A SINAGOGA DESENGANADA: UM TRATADO ANTIJUDAICO NO BRASIL DO COMEÇO DO SÉCULO XVIII
}

\author{
Bruno Feitler \\ Doutor em História pela École des Hautes \\ Études en Sciences Sociales (Paris)
}

\section{Resumo}

Em 1720 sai à luz em Lisboa a edição portuguesa da Sinagoga Desenganada, do jesuíta Giovanni Pietro Pinamonti. Estudamos aqui o contexto de tradução e de publicação desta obra ímpar pelos responsáveis por sua impressão: o jesuíta Andreoni e o arcebispo da Bahia D. Sebastião Monteiro da Vide. Vemos assim que no Brasil do século XVIII o medo da heresia judaica era uma realidade, e que do seu combate dependia a paz e o bem-estar geral.

\section{Abstract}

Sinagoga Desenganada, by the Jesuit Giovanni Pietro Pinamonti, is published in Lisbon in 1720. This article deals with the context of translation and publication of this original work because of those who published it: the Jesuit Andreoni, and the archbishop D. Sebastião Monteiro da Vide. We can see that in Brazil of the 18th century, the fear of the Jewish heresy was a reality, and that in order to achieve peace and well-being, one had to fight against it.

\section{Pallavras-Chave}

Literatura Antijudaica • Cristãos-Novos • Giovanni Pietro Pinamonti • Giovanni Antonio Andreoni • Sebastião Monteiro da Vide

\section{Keywords}

Anti-Jewish Literature • New-Christians • Giovanni Pietro Pinamonti • Giovani Antonio Andreoni • Sebastião Monteiro da Vide 
m 1720 sai à luz pela Oficina da Música de Lisboa uma obra bastante curiosa tanto por seu estilo como pelas pessoas responsáveis por sua publicação: a Sinagoga desenganada, tratado de conversão dirigido aos judeus, escrito originalmente em italiano pelo jesuíta Giovanni Pietro Pinamonti (1632-1703) e traduzido anonimamente no Brasil, sob o patrocínio do arcebispo da Bahia D. Sebastião Monteiro da Vide $^{1}$. Este livro se diferencia assim das outras obras escritas contra os judeus em Portugal durante a época moderna ${ }^{2}$.

Portugal não foi durante a Idade Média um país onde a controvérsia antijudaica (ao vivo, entre rabinos e sacerdotes, ou por escrito) fosse difundida, contrariamente ao que se verifica no resto da Europa. Paradoxalmente, foi somente depois do desaparecimento legal dos judeus, com a conversão forçada de 1497, que essa forma literária começou a ganhar importância, acabando por se enraizar no horizonte editorial lusitano. Com efeito, o "problema cristão-novo" gerou um número importante de obras (tratados, memoriais, sermões de auto-da-fé, panfletos) onde aqueles que se viam como os garantes da ortodoxia católica e muitas vezes, da integridade nacional, propunham seu método para acabar com o problema, seja por uma possível conversão sincera, seja pela expulsão dos cristãos-novos. De acordo com as obras mais conhecidas e difundidas - como o Breve tratado contra a herética perfídia do judaísmo de Vicente da Costa Mattos (1622), ou como a Sentinela contra os judeus, tradução da obra do espanhol Torrejoncillo (1684), sem falar na maioria dos sermões de auto-da-fé impressos -, era humanamente impossível converter sinceramente aqueles que os autores teimavam em chamar de judeus, mesmo dois séculos depois da conversão. Os autores de sermões, para guardar uma fachada devota, clamavam retoricamente pelo favor divino, enquanto autores como Costa Mattos, graças à ideologia racista que veiculavam (ligando a prática do judaísmo e o ódio dos cristãos-

\footnotetext{
${ }^{1}$ Sobre Pinamonti, veja-se a introdução das Opere do P. Pinamonti (Pinamonti 1706) ou ainda a sua biografia (Durazzo 1709). Nenhum dos dois textos menciona a importante produção literária do jesuíta.

${ }^{2}$ Agradeço aos amigos George Evergton Sales Souza e Nina Schipper pela leitura atenta que fizeram deste trabalho.
} 
novos aos "verdadeiros cristãos" a uma inexorável hereditariedade), concluíam sempre por pedir a expulsão dos supostos hereges e de suas famílias ${ }^{3}$. A Sinagoga desenganada - obra tardia escrita para a realidade da península italiana, onde os judeus, apesar do seu estatuto inferior, podiam praticar livremente sua religião nos interessa ainda pelo contexto brasileiro de sua tradução. Após descrevermos sua estrutura, veremos detalhadamente o que a distingue das outras obras do mesmo gênero para finalmente nos interessarmos pelas motivações que levaram à sua tradução e publicação.

\section{Estrutura da obra}

A obra começa, como era usual, por uma dedicatória. Neste caso se trata de uma dedicatória aos "Aos Senhores Inquizidores do Reyno e Conquistas de Portugal", assinada simplesmente pelo "Muyto humilde e obediente servo, o Traductor". Vêm em seguida as licenças do Santo Ofício, do ordinário e do Paço e o índice da obra. A Sinagoga divide-se em vinte e quatro capítulos, que formam três partes afora a introdução. A primeira parte trata dos "impedimentos que se atraveção ao conhecimento da verdadeyra Fè, e o modo de os tirar" (Pinamonti 1720: 4). Pinamonti começa por afirmar a existência de uma só religião (seita) verdadeira, "porque Deus não pode contradizer a si mesmo" (Pinamonti 1720: 13), sem fazer, no entanto, referência explícita ao catolicismo. Ele enumera em seguida as razões que fazem com que os judeus não consigam ver que a única verdadeira religião é a cristã: as paixões desordenadas (cap. IV), a inclinação ao negócio e a aversão às Letras e às Ciências, isto é, a submersão completa do ânimo "nas cousas temporaes" (cap. V), o fato de não pedirem a Deus a luz para encontrar a verdadeira religião

\footnotetext{
${ }^{3}$ Preparamos atualmente um estudo exaustivo sobre a literatura antijudaica portuguesa da Idade Moderna. Sobre alguns aspectos dessas obras, ver inter alii Glaser 1956, Révah 1975, Novinsky 1991 e Falbel 1999. ${ }^{4} \mathrm{~A}$ ortografia e a pontuação dos textos de época foram modernizadas para facilitar a leitura, mantendose as variações fonéticas.
} 
(cap. VI), o pecado (cap. VII), os "respeytos do mundo", isto é, da ordem presente das coisas, assim como o "amor que os seus lhes tem e o amor que elles tem aos seus" (cap. VIII), o fato de crer que se deve morrer na fé em que se nasceu (cap. IX). O capítulo VI contém uma "oração com que hum Hebreo poderà alcançar luz para conhecer a Fè verdadeyra" e o capítulo seguinte um "acto de arrependimento para alcançar de Deos o perdão dos peccados e se dispor hum Hebreo de algum modo para conhecer a Fè verdadeyra" ${ }^{5}$.

Na segunda parte Pinamonti descreve os sete atributos, ou sinais, necessários para se reconhecer a verdadeira Fé. Esta parte, subdividida em oito capítulos - um de introdução e um para cada "sinal" (cap. X-XVII) - trata de demonstrar a verdade do cristianismo comparando-o ao judaísmo. Contrariamente a seus colegas tratadistas portugueses, o autor procura fazê-lo de modo construtivo, mostrando a existência de uma verdadeira continuidade entre o judaísmo e o cristianismo. Os atributos utilizados baseiam-se em temas comuns da literatura de polêmica: a santidade da lei, o testemunho da profecia, o testemunho dos milagres ou ainda o testemunho dos mártires. Contudo, ele não os discerne unicamente na fé cristã, mas demonstra igualmente como antes da vinda de Jesus, todos esses atributos eram próprios ao judaísmo ${ }^{6}$.

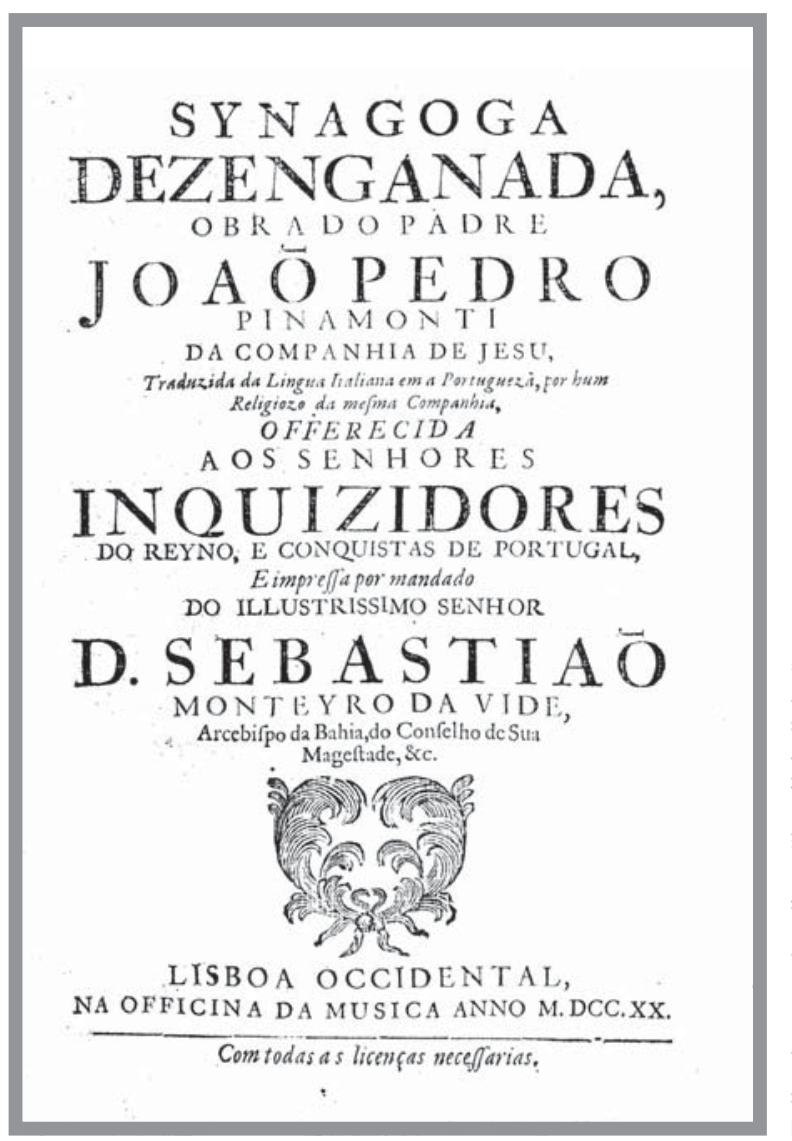


A terceira parte (cap. XVIII-XXIV) dedica-se a responder "as principaes difficuldades que costumão, ou podem propor os Rabinos à Doutrina que vos tenho declarado" (Pinamonti 1720: 304), perfazendo um total de sete questões. Pinamonti começa pela mudança de lei (cap. XVIII), a ab-rogação da circuncisão, das leis alimentares e do descanso sabático (cap. XIX). Ele continua sobre o não reconhecimento do messianismo de Jesus pelos judeus da sua época (cap. XX) e pela afirmação dos judeus de que as profecias ainda não se haviam cumprido (cap. XXI). A quinta e a sexta dificuldades tratam do reconhecimento do mistério da Trindade (cap. XXII) e da aversão dos judeus à idéia de adorar um homem crucificado e sua imagem (cap. XXIII). A terceira parte termina por dar as razões da má vida dos cristãos (cap. XXIV). O livro em si acaba com um epílogo, seguido do texto dos "Privilegios concedidos aos Hebreos e a outros infiéis que se fazem Christãos, sobre suas heranças, dotes, legitimas e bens adventicios, conteudos em huma Bulla do papa Clemente XI. N. S., na qual renova outra do Sumo Pontifice Paulo III e exhorta paternalmente aos Bispos e aos Pregadores para que tratem com todo o cuidado e amor da conversão delles; e aos Principes e Senhores Christãos para que sejam seus Protectores e defensores. E geralmente a todos os Christãos, para que os favoreção como irmãos regenerados em Christo S.N. pelo Santo Bautismo "." A conservação do texto da bula na versão portuguesa demonstra claramente o papel evangelizador que os res-

\footnotetext{
${ }^{5} \mathrm{Na}$ versão original, Pinamonti utiliza indiferentemente os vocábulos Ebreo e Giudeo (p. ex. "In prima, la miseria degli Ebrei non può essere prova..." e "Non può dunque chiarmarsi Prova la miseria de' Giudei...”. (Pinamonti 1706: 521), preferindo, entretanto, o primeiro termo. O tradutor da versão portuguesa seguiu a mesma terminologia, escrevendo Hebreu para traduzir Ebreo, e Judeu para traduzir Giudeo, apesar da grande diferença de uso desses termos nessas duas línguas.

${ }^{6}$ Pinamonti introduz nesta parte um atributo que me parece ser pouco mencionado por este tipo de literatura: a sapiência (cap. XII). Ele demonstra em primeiro lugar que os antigos hebreus possuíam essa sabedoria mas que eles a perderam, o Talmud não sendo mais que fábulas. Já o cristianismo revelou ao mundo a verdadeira sabedoria não só no que toca às coisas divinas, mas também no que diz respeito ao conhecimento humano.

${ }^{7}$ Assim está resumido o conteúdo da bula no índice da obra. O texto da bula encontra-se às p. 266279. Com data de 11 de março de 1703 , esta bula obviamente não se encontra na primeira edição italiana da Synagoga (1694).
} 
ponsáveis pela tradução atribuíam não só aos eclesiásticos mas também aos laicos, poderosos ou não. Este posicionamento em prol de uma política de evangelização era uma novidade quando se considera a agressividade da maioria das obras de polêmica editadas em Portugal antes da Sinagoga.

Já a licença do Paço reflete as diferentes opiniões que os letrados portugueses podiam ter do problema cristão-novo. O oratoriano Pedro Álvares começa por denunciar "o quasi paradoxo" prometido pelo título da obra, visto "a larga experiencia da inflexivel obstinação e affetada cegueyra com que os Hebreos não sómente forcejão por segurar nos olhos o veo com que resistem á luz da verdade, mas àlem disso buscão, seguem, abração e adorão as mal formadas quimeras de seus aereos e futeys enganos". Ele acaba, entretanto por elogiar o trabalho, tanto do autor como do tradutor da obra:

“estes nossos Apostolos (como os primeyros a quem imitão) não são todos das Gentes, como Paulo, más tambem alguns são Apostolos dos Circuncidados, como Pedro. Pois ao mesmo tempo que voluntariamente se desterrão muytos por buscar e reduzir aos Gentios, se ocuppão outros em convencer e dezenganar aos Judeos. Se ainda entre nós vivem alguns inclinados de coração aos seus erros, ou duvidozos da nossa verdadeyra Fé, neste livro (se os não desviar da sua lição o seu mesmo titulo) acharão doutrina que facilmente instrúa e verdade que poderozamente os desengane; e por este meyo não terá V. Majestade Vassalos que não sejão fieis".

Podemos vislumbrar aqui duas vertentes da literatura portuguesa antijudaica, quase antinômicas, que se ajuntam: o oratoriano constata primeiro as dificuldades que supõem a tarefa de converter os judeus para depois elogiar aqueles que se empenham sinceramente, como Pedro, na conversão dos "circuncisos". Foi nesta via que Pinamonti e os responsáveis da tradução portuguesa de sua obra se engajaram.

\footnotetext{
${ }^{8}$ Os três últimos são judeus convertidos do século XV, Galatino na Itália, Santa Maria e Santa Fé na Espanha.
} 


\section{Uma obra diferente}

A Sinagoga se distancia das obras antijudaicas portuguesas de mesma importância por sua serenidade. Apesar das pretensas intenções pedagógicas com relação aos judaizantes, estas obras acabavam na maioria das vezes por se tornar uma série de insultos e de calúnias. Para redigir a Sinagoga, Pinamonti utiliza os mesmos textos de base da produção antijudaica do período patrístico e tardo-medieval que seus colegas portugueses: são Jerônimo, são João Crisóstomo, Nicolau de Lira, Pietro Colonna (Galatino), Pablo de Santa Maria, Jerônimo de Santa Fé ${ }^{8}$, etc., mas evita insultar os judeus em geral,

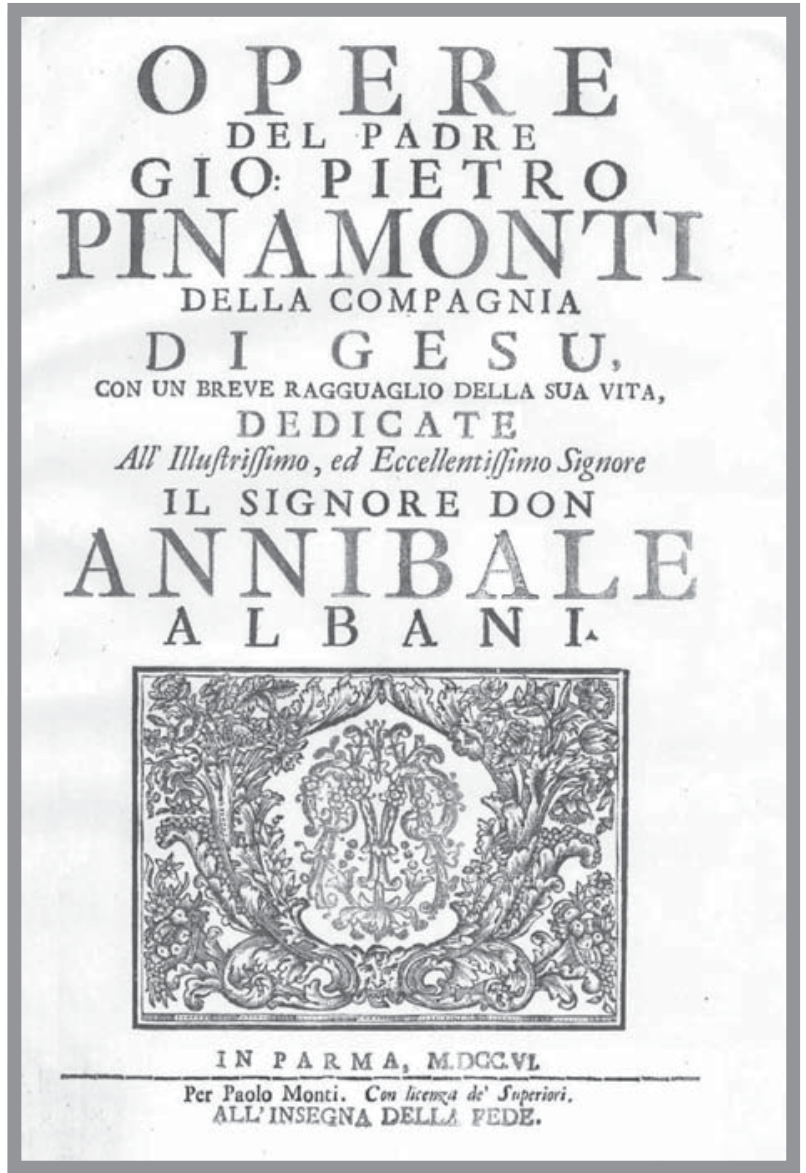
prometendo fugir de ser maldizente (Pinamonti 1720: 10), e atribui toda a culpa de um suposto ódio dos judeus em relação aos cristãos somente aos rabinos. O autor pede finalmente às pessoas de boa fé que liberem seus corações de todo ódio e orgulho. Inspirando-se provavelmente nos Erros dos judeus tirados do Talmud, de Jerônimo de Santa Fé (cf.

Folha de rosto das Opere de Pinamonti de 1706, edição utilizada por Andreoni para sua tradução da Sinagoga. 
Orfali s.d.), menciona um preceito talmúdico que diz que os judeus são obrigados a "aborrecer aos Christãos, tendo-os em conta de bestas e amaldiçoando-os". Entretanto, Pinamonti prossegue: "eu não creo que os Hebreos modernos guardem esta ley tão iniqua", mesmo se ele dá crédito aos relatos de assassinatos rituais e de pactos com o inimigo - neste caso, os turcos (Pinamonti 1720: 19-20). Na sua refutação do Talmud e nos relatos que faz das expulsões da Europa medieval e dos assassinatos rituais, ele parece até se cansar de tanto horror ao dizer "verdadeyramente tenho pena de havervos de dizer frequentemente cousas de muyto desgosto"; ele parece encarar sinceramente esses relatos como exemplos pedagógicos e não como desculpa para desprezo: "como se ha de curar a chaga se senão descobre ? Não digo por escarneo, mas por remedio o que agora hey de accrecentar"(Pinamonti 1720: 81).

Assim, ele se nega a ver todos os judeus, tanto do passado como do seu tempo, como uma única entidade. Ao referir-se às expulsões da França e da Inglaterra, Pinamonti diz:

"Nem quero com isto dizer que se haja de crer que em todos estes cazos [os sacrilégios utilizados como desculpa de algumas expulsões] todos os Hebreos fossem igualmente culpados naquellas maldades pelas quaes eram castigados, devendose, como agora, assim então, achar entre elles alguns ornados de varias virtudes moraes, amantes do justo e afastados de semelhantes delictos. Com tudo, prudentemente julgavão os Principes que a nação Judaica devia tirarse do meio dos Reynos, porque de tempo em tempo com taes excessos perturbava o bem publico (Pinamonti 1720: 227-228)."

Pinamonti deixa assim subentendida a idéia de que a ordem pública era mais importante que a gravidade dos delitos cometidos! Este e outros trechos mostram ainda que a obra não se adaptava a realidade ibérica. Isto fica patente em certas partes, onde Pinamonti descreve como os judeus eram tratados em terras cristãs ${ }^{9}$. Chega a parecer

\footnotetext{
${ }^{9}$ P. ex.: "em nenhum lugar do mundo são tratados melhor que entre os Christãos, aonde, tirando algum insolente, todos os deyxamos viver em paz e os melhores entre nòs se compadecem delles como de enganados, rogando a Deos instantemente que seja servido alumiallos e os Magistrados lhes administrão inteyra justiça como a qualquer outro Christão", (Pinamonti 1720: 19) e "nunca
} 
estranho que a Sinagoga tenha recebido todas as autorizações para ser impressa, mesmo se o lapso de dois anos entre as datas das licenças (maio, agosto e outubro de 1718) e de sua publicação (1720) possa ser o indício de certos problemas.

Devemos agora ler a versão portuguesa mais de perto. Não me parecia necessário fazer uma confrontação entre o texto com seu original italiano; à primeira vista a tradução parecia ser das mais fiéis. Contudo, pelo menos uma vez, o tradutor deixou correr suas próprias idéias. O parágrafo 153 (que faz parte do capítulo XVI) da edição portuguesa é o seguinte:

"Esta mesma inconstancia se manifesta cada anno nos actos publicos da Fè pela Santa Inquizição, aonde se declarão os delictos plenamente provados dos que fingidamente abraçarão e professarão a Fé Christãa, movidos do interesse ou de outros respeytos temporaes e depois occultamente exercitarão os Ritos e ceremonias Judaicas com desprezo da Ley e da Pessoa de Jesu Christo, a quem tinhão reconhecido por verdadeyro Messias. E nestes casos não se castigão por serem Judeos de nação, mas por serem Christãos fingidos com injuria da Fé Christãa que mostrarão crer e seguir, podendo, se quizessem, não se bautizar e continuar como antes na profissão do Judaismo, com publico sinal nas suas sinagogas, aonde não são perseguidos e aonde se tolerão com a esperança de serem reduzidos a Fé Christãa que se lhes prega, e por se fingirem tambem os seus descendentes Christãos com desprezo de Christo e dos Sacramentos por ele instituidos, que sacrilegamente recebem. E nestes mesmos castigos se manifesta a clemencia da Igreja, admittindo a confissão voluntaria dos Reos, e a retractação dos mesmos legitimamente convencidos e a promessa da emenda ${ }^{10}$, a que facilmente faltão com peyores reincidencias, pelas quaes merecem finalmente o devido suplicio ${ }^{11}$, executado pelos Ministros dos Principes" (Pinamonti 1720: 230-231).

forão perseguidos athe á morte os Hebreos por causa da sua Fé, dos senhores Christãos. Mas antes, se tal vez da insolencia militar dos soldados ou da liberdade do povo forão maltratados, os nossos Principes hão tratado da sua defeza e de reprimir com leys opportunas assim ao povo como aos soldados" (Pinamonti 1720: 228).

${ }^{10}$ Trata-se das pessoas "reconciliadas" com a Igreja, isto é, das pessoas que eram reconhecidas como culpadas e em seguida perdoadas pela Inquisição após terem confessado inteiramente os crimes que lhes eram imputados.

${ }^{11}$ Segundo a legislação inquisitorial, as pessoas acusadas uma segunda vez por heresia (após um primeiro julgamento e reconciliação), eram entregues, ou de acordo com o jargão inquisitorial, relaxadas ao braço secular para serem executadas na fogueira, não tendo assim direito à "misericórdia" dos juizes. 
A partir daí a tradução portuguesa retoma o texto original deste parágrafo, onde Pinamonti não faz mais que concluir sobre o que havia escrito sobre os castigos recebidos pelos judeus e sobre a inexistência de mártires judeus após a vinda de Jesus, encadeando assim com a parte sobre o testemunhos dos mártires do cristianismo. Antes de tudo, parece evidente que o tradutor faz aqui referência a uma realidade ibérica e mais particularmente portuguesa - visto que durante o século XVIII a Inquisição romana teve que se ocupar poucas vezes de casos de cripto-judaísmo -, mas sobretudo porque escrever sobre "judeus de nação" e "seus descendentes cristãos" remete diretamente à situação dos cristãos-novos da península ibérica e de seus domínios. Parece entretanto estranho que o tradutor tenha ousado mencionar a alternativa de "continuar como antes na profissão do judaísmo, com público sinal nas suas sinagogas" ou de uma possível tolerância; temas que neste caso correspondem mais a uma realidade italiana que ibérica. Este cinismo pode-se explicar por uma vontade do tradutor de disfarçar seu acréscimo, primeiramente pela omissão da "nacionalidade" de uma Inquisição em particular (neste caso a portuguesa) e em seguida por esta mistura de contextos, para deixar entender que escrevia sobre a Itália, onde vários estados toleravam a prática do judaísmo.

Por um lado, podemos concluir deste trecho que o tradutor sentiu a necessidade de discorrer, mesmo que de modo breve e furtivo, sobre o problema dos cristãosnovos do mundo português, motivo principal que, como veremos, levou-o a se lançar na tradução deste livro. Vemos ainda que ele aprova inteiramente o procedimento jurídico da Inquisição portuguesa, achando entretanto necessário afirmar que nem todo cristão-novo é automaticamente um judaizante. Por outro lado, se tomamos em conta a menção de sinagogas públicas e de uma certa tolerância como opiniões pessoais do tradutor, temos que crer que ele não se oporia à existência de judeus confessos e não batizados em terras portuguesas.

\section{0 jesuíta e o arcebispo}

Como explicar a escolha desta obra por religiosos habitantes da América portuguesa e a necessidade que tiveram de traduzir e de publicar um tratado antijudaico? 
O arcebispo da Bahia, Dom Sebastião Monteiro da Vide, que subvencionou a publicação da Sinagoga, não se pronunciou. Na dedicatória aos "senhores inquisidores do reino e conquistas de Portugal", o tradutor anônimo (segundo Serafim Leite [19381950: t. VIII, p. 45] se trata de João Antônio Andreoni) só faz uma pequena menção do contexto local que o levou a traduzi-la do italiano, dizendo que com ela esperava

\begin{abstract}
"alumiar por este meyo, quanto for possivel, aos cegos, e para confirmar aos que por Mizericordia de Deos vem mas não dão graças a Deos pela luz que lhes tem communicado no Santo Bautismo, e muyto mais para acodir aos que dão entrada às duvidas que lhes offerece o commum inimigo, ou que por terem nas veas algum sangue da nação Hebrea, são mais facilmente tentados e ainda mizeravelmente vencidos, vacillando ou cahindo como se vè frequentemente nos Actos da Fè, e como tem mostrado a experiencia nestes ultimos annos, com mayor ruina em algumas partes do Brazil, aonde assisto".
\end{abstract}

Infelizmente esta é a única referência local existente no texto; nem o tradutor, nem os censores deixaram outras pistas do contexto em que a obra foi editada. Vejamos então o que se passava no Brasil no momento da sua tradução.

Andreoni morreu em março de 1716, e como ele mesmo afirmou, os casos de moradores do Brasil condenados por judaísmo no começo do século XVIII foram abundantes. Entre 1700 e 1718, 214 moradores do Rio de Janeiro foram reconciliados pelo Santo Ofício, relaxados ao braço secular (isto é, executadas na fogueira) ou ainda absolvidos. Mas devemos pensar que ele se referia mais especificamente aos casos ocorridos na Bahia - onde residiu entre 1681 e 1716 -, lugar de origem de 15 pessoas "saídas" em autos-da-fé entre 1701 e 1716, o que pressupõe terem sido presas na Bahia em geral entre 2 e 4 anos antes dessas datas (cf. Varnhagen 1845, Novinsky 1992 e Dines 1992: 915-975). Além desses dados, temos que levar em conta que seu cargo de provincial jesuíta deve ter feito com que tivesse uma correspondência assídua com os membros da Companhia de Jesus do Rio de Janeiro e ter assim ecos dos casos que aí se davam. A tradução foi feita nessa época de perseguição ao judaísmo, entre 1706 (ano da primeira edição da obra de Pinamonti com o texto da bula de Clemente XI) e 1716 (ano da morte de Andreoni) ${ }^{12}$. 
Temos que nos debruçar com mais atenção sobre a personagem de Andreoni, visto que a escolha da tradução foi sua. Antes de tudo sobre a identificação que Serafim Leite faz do tradutor, que querendo guardar o anonimato, só declina, no título mesmo da obra, sua profissão jesuíta, deixando igualmente claro não ser de língua materna portuguesa; o anônimo escreve : "mas como em mim a língua portuguesa não é natural, mas mal aprendida e por isso mal falada" (Pinamonti 1720: dedicatória). A Bibliothèque de la Compagnie de Jésus, a fonte de Serafim Leite no que toca a atribuição da obra, utiliza um catálogo manuscrito de autores brasileiros feito em latim pelo Padre Lopez de Arbizu, e que não pude, até agora, encontrar

\footnotetext{
${ }^{12}$ A Sinagoga saiu pela primeira vez em italiano em 1694 em Roma e em Bolonha. Não pude verificar se se trata de duas edições ou somente de duas impressões diferentes. Fizeram-se mais duas edições isoladas da obra (Veneza, 1754 e Nápoles 1911), e várias outras (um total de nove entre 1706 e 1767) integrando as Opere del Padre Gio: Pietro Pinamonti della Compagnia di Gesu, con un breve ragguaglio della sua vita. Neste artigo utilizamos a primeira edição das Opere (Pinamonti 1706), a mesma utilizada para a tradução portuguesa. Para as diferentes edições, veja Sommervogel 18901909: t. VI, col. 775 e 791. A tardia edição de Nápoles (Pinamonti 1911), é uma reutilização interessantíssima dos argumentos de Pinamonti, que provam aqui terem atingido (de modo semelhante à irracionalidade característica do anti-semitismo ibérico), a universalidade desejada no título da primeira edição. A edição napolitana foi feita em um contexto de insegurança religiosa bastante diferente do brasileiro, quando certos membros da Igreja sentiram-se ameaçados pela maçonaria e pelas idéias liberais. Seguem trechos da nota introdutória do editor: "Ti recherà maraviglia, e ti muoverà l'animo a derisione, o mio buon lettore, veder pubblicato un Opusculo per la stampa [...] una operetta, che a primo intuito ha perduto ogni valore nel secolo nostro, il quale lascia la questione religiosa solamente a quei, che non hanno di che occuparsi. Affrontare il Giudaismo, di cui solo il nome oggi è rimasto: ma... a qual pro?! Eppure non è cosí. S'ingannerebbe assai chi cosí la pensasse. Oggi che la Massoneria domina il mondo intero e, rovesciando troni, vorrebe svellere fin dalle fondamenta l'Altare Cattolico, oggi a preferenza di ogni altra epoca vi è bisogno di smascherare ed atterrare l'Ebraismo. Da questo in vero è, che discende e vien diretta l'odierna setta Massonica. Sono gli Ebrei oggi, che, transformatisi in Massoni, sotto la maschera di civiltà, progresso, libertà combattono la Chiesa Cattolica, ed impadronendosi delle Cattedre, delle Amministrazioni, delle sostanze dei popoli, ne vogliono la rovina temporane ed eterna. Troppo a proposito si presenta perciò questo libretto al publico: libretto piccolo nella sua mole, ma grande e sublime nella sua dottrina, colla quale svela tutta l'ipocrisia e la malvagità dei persecutori del Cattolicismo, mascherati da Frammassoni. [...] Voglia Dio Benedire questa pubblicazione, affinchè pervenendo essa nelle mani dei Giudei, Protestanti, ed odierni Liberi Pensatori, li illumini e li converta. Sii sano.”
} 
(Sommervogel 1890-1909: t. I, col. 340-341 e t. VI, col. 775) ${ }^{13}$. Barbosa Machado (1741-1759) não inclui a Sinagoga em sua Biblioteca, provavelmente, como já o disse Andrée Mansuy Diniz Silva (2001: 22), referindo-se ao outro trabalho de Andreoni, por causa da origem italiana do autor e do tradutor ${ }^{14}$. O bibliógrafo Antônio Ribeiro dos Santos (1806: 374-377) não menciona o nome do tradutor, citando entretanto a obra entre as outras produções portuguesas antijudaicas. O pseudônimo em forma de anagrama que dá uma pista do nome real do autor da Cultura e Opulência do Brasil por suas drogas e minas, infelizmente não se repete quando se trata do tradutor da Sinagoga. Apesar da existência de outros autores jesuítas italianos no Brasil na mesma época, como o vice-provincial Estêvão Gandolfi, falecido no Rio de Janeiro em 1720 (Leite 1938-1950: t. VIII, p. 266), não há razões para pôr em dúvida a fonte da Bibliothèque de la Compagnie de Jésus.

Giovanni Antonio Andreoni nasceu em 1649 em Lucca, na Toscana. Após três anos de estudos de direito civil em Perugia, ele entrou em Roma, na Companhia de Jesus (maio de 1667). Era Professor de Humanidades e repetidor de Retórica e de Filosofia no Colégio romano quando, em 1681, instigado por Antônio Vieira, embarcou para a Bahia. Ali fez profissão solene e ocupou, além do cargo importantíssimo de provincial, o de professor de retórica, de diretor da congregação dos estudantes e de reitor do Colégio da Bahia, afora suas funções de visitador e de pregador. Participou ativamente das controvérsias que dividiam os jesuítas da Bahia, formando um grupo de italianos e de alemães que se opunha às idéias de seu antigo mentor, Antônio Vieira, e de outros jesuítas portugueses. Segundo Serafim Leite, as divergências tocavam a questão da escravidão dos índios, mas também a questão dos "judeus": "Vieira não atacava os judeus; Andreoni traduziu contra eles a Sinagoga

\footnotetext{
${ }^{13}$ Procurei o catálogo tanto nos Arquivos da Companhia em Roma quanto em Paris, onde, segundo Sommervogel, se encontraria uma cópia, que aparentemente perdeu-se com os distúrbios causados em 1905 pela separação da Igreja e do Estado na França.

${ }^{14} \mathrm{O}$ sucessor de Barbosa Machado, Innocêncio F. da Silva (1858) tampouco menciona a obra, provavelmente pelas mesmas razões.
} 
Desenganada" (Leite 1938-1950: t. VIII, p. 45). São essas controvérsias (mesmo após a morte de Antônio Vieira em 1697) e o desrespeito à legislação real proibindo estrangeiros em postos de importância na Província do Brasil, que podem explicar a escolha do anonimato de Andreoni na publicação tanto da Cultura e opulência do Brasil, como da sua tradução da Sinagoga desenganada. Andreoni morreu na Bahia no dia 13 de março de 1716.

A idéia de se publicar uma obra antijudaica entende-se mais facilmente quando se leva em conta o ambiente pesado que devia pairar sobre a Bahia naquela época. A Inquisição era normalmente bastante circunspecta no seu funcionamento; as missões feitas em seu nome o eram por oficiais locais (comissários, familiares) ou por religiosos nomeados especialmente para a ocasião, que faziam as inquirições o mais discretamente possível. As prisões, até então pouco numerosas, deviam marcar os espíritos de modo mais forte e duradouro do que os simples inquéritos. Dentre as prisões efetuadas na Bahia, duas devem ter chamado especialmente a atenção dos moradores da capital da colônia no começo do século XVIII: Rodrigo Álvares, boticário de 32 anos natural de Avis, preso na Bahia em 1705, foi queimado em Lisboa após o auto-da-fé de 30 de junho de 1709, e Diogo Rodrigues, judeu francês não batizado, saiu no auto-da-fé de 9 de julho de $1713^{15}$. Esses casos são verdadeiramente incomuns, devendo ter espantado a população local; o segundo por sua estranheza

\footnotetext{
${ }^{15}$ Cf. Varnhagen 1845, Novinsky 1992 e Dines 1992: 915-975. Diogo Rodrigues (aliás Dioguinho Hebreu), cujo verdadeiro nome era Abraão Rodrigues, nasceu em Vidaxe (sul da França) em 1664 e foi preso de passagem pela Bahia em 1712. Ele era o filho de Mateus Mendes de Leão e de Beatriz Rodrigues, naturais do Porto. Aos 20 anos ele parte para a cidade natal de seus pais, mudando-se oito meses depois para o Rio de Janeiro onde vivia como comerciante e onde se dizia batizado, o que lhe valeu penas de "galés e açoutes ". Os inquisidores previram a comutação das penas se Diogo se batizasse, visto ele ser " digno de algum favor por ser homem vil, pobre, de pouca arte e indústria e nem se presumir dele esta fraude, nem que se fingira cristão em desprezo da religião católica e dos sacramentos ou por ensinar aos cristãos-novos a lei de Moisés, mas somente para poder sustentar a vida ". Arquivos Nacionais/Torre do Tombo, Inquisição de Lisboa, processo 5336. Ele recebeu finalmente o batismo em 29 de julho de 1713, vinte dias depois do auto-da-fé em que saiu, na Sé de Lisboa, com o nome de Manoel Rodrigues Leão. Arquivos Nacionais/Torre do Tombo, livro de batismos, Lisboa, Sé, caixa 3, n 8 , fl. 90.
} 
e o primeiro por sua raridade: não foram muitos os moradores do Brasil "relaxados ao braço secular". Vale lembrar que após a execução de um herético na fogueira, seu retrato era enviado à paróquia de residência e pendurado na porta da matriz, imprimindo assim no espírito de seus ex-vizinhos o poder do longo braço inquisitorial e a gravidade do pecado cometido. Foram provavelmente estes fatos que motivaram Andreoni a tomar alguma providência. Também temos que levar em conta que no começo do século XVIII os oficiais da Inquisição na Bahia eram muitos: entre 1683 e 1704, 108 nomeações, sobretudo de familiares, foram emitidas em nome de habitantes do arcebispado da Bahia (Arquivos Nacionais/Torre do Tombo, Inquisição de Lisboa, livro 107). Eram não só numerosos, mas também organizados. Em 1697, no dia de são Pedro Mártir, padroeiro dos oficiais do Santo Ofício, organizam pela primeira vez festividades em sua honra, chegando mesmo a publicar o sermão que foi então pregado (Jesus 1700).

As razões da escolha do título a ser traduzido são mais complexas. Andreoni dá suas razões na dedicatória da Sinagoga ao comparar o papel do Santo Ofício e as qualidades da obra:

\begin{abstract}
"Por ser o fim principal do Tribunal sagrado da santa Inquizição, conservar na sua pureza a Fè Christãa com huma continua vigilancia, ordenada a prohibir, evitar e castigar qualquer culpa que a pode de algum modo offender e reduzir a ella os incredulos e confirmar na sua crença aos que fielmente a professão; como não sey que athegora a tenha sahido à luz, entre muytas e muyto boas obras que se divulgarão, outra mais accomodada a este fim que a que agora offereço ao mesmo Santo Tribunal, parece que neste offereccimento não mereço a nota de confiado."
\end{abstract}

Ele indica então conhecer outras obras do mesmo tipo, mas que não lhe parecem convir. Seria por ele ser italiano, contemporâneo de Pinamonti e membro da mesma Companhia de Jesus? A "nacionalidade" do tradutor também pode subentender que antes de sua partida para Portugal e depois para o Brasil, tenha entrado em contato, não com a obra (pois ele se foi antes da primeira edição italiana), mas com judeus do gueto de Roma, por exemplo, cidade onde Andreoni ensinou até sua partida. Esta experiência direta da existência de judeus "oficiais" pode tê-lo tornado refratário, 
pelo menos em parte, aos preconceitos portugueses e à sua exaltação anti-semita, sem impedi-lo, entretanto, de crer na necessidade de se tomar uma providência para converter sinceramente os judaizantes do Brasil.

Outras obras em português poderiam convir à situação. Os dois livros publicados pelo converso de origem italiana João Batista d'Este têm o mesmo espírito evangelizador que a Sinagoga, principalmente o Diálogo entre discípulo e mestre catequizante, publicado pela primeira vez em 1621 e reeditado em 1679 e que de maneira didática resolve todas as dúvidas que os judeus obstinados costumam fazer contra a verdade da Fé católica. Ou Andreoni estava a par de que esta obra não passava de um vergonhoso plágio de um tratado escrito em italiano pelo professor de hebraico da Colégio dos catecúmenos de Roma (o que não parece ter sido do conhecimento geral na época) ${ }^{16}$, ou simplesmente preferiu uma obra mais recente, escrita por um jesuíta como ele.

É mais difícil de entender a razão da escolha de Sebastião Monteiro da Vide, quinto arcebispo da Bahia e financiador da publicação da Sinagoga. Como todo eclesiástico de seu nível, ele devia se corresponder com o Santo Ofício, transmitindo aos inquisidores toda denúncia que não fosse de sua alçada. Durante o sínodo diocesano de 1707, que resultou na publicação das Constituições primeiras do arcebispado da Bahia, D. Sebastião foi auxiliado por vários oficiais da Inquisição; a pessoa mais importante depois dele enquanto promotor do sínodo, o cônego João Calmon, era comissário do Santo Ofício e a Inquisição tem seu lugar no próprio texto das Constituições. O parágrafo 886, título I do livro 5 diz que

"Para que o crime da heresia e judaismo se extinga e seja mayor a gloria de Deos nosso Senhor e augmento de nossa Santa Fé Catholica, e para que mais facilmente possa ser punido pelo Tribunal do Santo Officio o delinquente, conforme

\footnotetext{
${ }^{16} \mathrm{O}$ nome do verdadeiro autor é Fabiano Fioghi e a obra intitula-se Dialogo fra il cathecumeno et il padre cathechizante [...] Nelqual si risoluono molti dubij, liquali fogliono far li Hebrei, contro la uerità della santa fede Christiana: con efficacissime ragioni: \& per li santi Profeti, \& per li Rabini, publicada em Roma em 1582.
} 
os Breves Apostolicos concedidos à instancia dos nossos Serenissimos Reys a este sagrado Tribunal, ordenamos e mandamos a todos os nosso subditos, que tendo noticia de alguma pessoa ser herege, Apostata de nossa Santa Fè ou Judeo, ou seguir doutrina contraria àquella que ensina e professa a Santa Madre Igreja Romana, a dennunciem logo ao Tribunal do Santo Officio no termo de seus Editaes, ainda sendo a culpa secreta, como for interior."

Como as Constituições foram redigidas a fim de adaptar os regulamentos apostólicos à realidade baiana, devemos crer que Monteiro da Vide achava importante e útil inserir este parágrafo na sua obra. A publicação da Sinagoga é apenas uma prova a mais da sua preocupação em relação ao judaísmo no seu arcebispado.

Em uma carta enviada no ano de 1711 ao general Tamburini em Roma, Andreoni vangloria-se de ser o conselheiro do arcebispo Dom Sebastião Monteiro da Vide que, apesar de seus conhecimentos em Direito, o escolheu como censor e revisor secreto das constituições sinodais, além de consultá-lo e seguir seus conselhos em casos de conflito com os ministros reais (Leite 1938-1950: t. VII, p. 113-114). Ele pode assim ter aceitado a escolha de Andreoni de publicar a Sinagoga.

\section{Uma obra representativa da política jesuíta?}

Analisamos o conteúdo da Sinagoga e o contexto local que levou à sua tradução e publicação. Devemos agora inseri-la no contexto mais amplo da produção de obras antijudaicas portuguesa e encontrar a origem do espírito evangelizador que faz sua especificidade. Os primeiros tratados portugueses do gênero, seguindo a tradição medieval, tinham como objetivo converter os judeus, isto é, no caso português, levar sinceramente ao cristianismo os recém-convertidos. Esse momento prolonga-se até princípios do século XVII, quando começa um novo período. A partir daí as conotações raciais, anti-semitas, sobressaem claramente das obras e essa guerra literária contra os cristãos-novos durará até a segunda metade do século XVIII, quando o decreto de Pombal que aboliu a distinção entre cristãos-novos e cristãos-velhos (25 de maio de 1773 ) põe este gênero literário na clandestinidade. Durante todo esse tempo há um crescendo do caráter racista das obras, e mesmo se no século XVIII a literatura 
antijudaica se renova pouquíssimo - há poucas criações depois da segunda metade do século XVII -, a quantidade de reedições e a tradução da obra de Torrejoncillo mostram que o anti-semitismo estava então no seu auge. A tradução e a publicação de uma obra do gênero da Sinagoga parece assim fora de contexto nos anos 1720.

Vejamos agora mais em detalhe qual era a política da Companhia de Jesus em relação aos judeus e aos cristãos-novos. O fundador da Companhia, Inácio de Loyola, não escondia seus sentimentos em relação à política ibérica de pureza de sangue. Ele aceitava de bom grado os cristãos-novos na sua ordem e tinha projetos proselitistas em relação aos judeus. Com efeito, uma das primeiras formas do apostolado de Loyola materializou-se, em 1543, pela fundação da Casa dos Catecúmenos de Roma, instituição dedicada à instrução e à conversão de judeus, muçulmanos e protestantes (cf. Collenberg 1986: 91-95). Contudo, nem todos seus sucessores pensavam do mesmo modo que ele e após uma longa controvérsia a entrada de cristãos-novos na ordem foi proibida em 1593, em seguida novamente permitida (a partir de 1608), sob a condição de ser católico em pelo menos cinco gerações (Alden 1996: 258). O que se pode notar é que, apesar desta legislação (nem sempre aplicada), os jesuítas não abandonaram suas resoluções em relação aos judeus: a obra de Pinamonti e a fundação de novas Casas dos Catecúmenos na Itália e também em Portugal o provam ${ }^{17}$. Mas seria essa política aplicada, em Portugal, igualmente aos cristãos-novos, sempre assimilados aos judeus? A autoria de quatorze sermões de auto-da-fé publicados parece dizer o contrário, pois eles repetem a virulência e o vocabulário humilhante habitual neste tipo de publicação. Devemos crer que Andreoni, ao traduzir a Sinagoga em português, agiu como seguidor da tradição jesuíta italiana, assimilando porém certas noções ibéricas: ele identifica os cristãosnovos, cujos ancestrais haviam sido convertidos mais de duzentos anos antes, aos judeus confessos, praticantes legais do judaísmo no resto do mundo.

\footnotetext{
${ }^{17}$ A Casa dos Catecúmenos de Lisboa só admitia judeus confessos não batizados, vindos sobretudo da África do Norte (cf. Stuczynski 1999: 173-201).
} 
Analisemos finalmente as divergências existentes entre Antônio Vieira e Andreoni mencionadas por Serafim Leite. Não podemos nos pronunciar sobre a questão da escravidão indígena, mas quanto à questão dos judeus, podemos afirmar que os dois jesuítas tinham idéias bastante próximas. Para eles, o judaísmo é uma religião falsa que deveria ter-se extinguido depois da vinda de Jesus ${ }^{18}$, mas isto não implica que considerassem todos os cristãos-novos como possíveis apóstatas. Para eles, os estatutos de pureza de sangue, característica máxima do racismo ibérico, não deviam existir. Andreoni não se ilustrou especialmente na defesa da causa dos cristãos-novos e Vieira não se interessou diretamente pela controvérsia religiosa; cada um em seu tempo investiu no que lhe parecia mais urgente. Entretanto, divergiam completamente sobre o papel da Inquisição: após a luta aberta que travou contra o Santo Ofício, Vieira nunca dedicaria uma obra aos inquisidores que lhe causaram tantos males. Já Andreoni, por meio do trecho que inseriu na obra de Pinamonti todo à glória do Santo Ofício, mostrou claramente ter sido um incondicional dos métodos inquisitoriais vigentes em Portugal.

De qualquer modo, Andreoni, tanto quanto Vieira, parecia não querer mais que o bem público e a grandeza do império português: Vieira, missionário, político e

\footnotetext{
${ }^{18}$ Para Viera, ver por exemplo, História do Futuro, cap.10, \$205, onde o judeu é apresentado como o paradigma da teimosia: "[...] Não basta só que Deos tenha revelado os futuros, he necessario que revele tambem os olhos. Revela oculos meos. Se os olhos estão cubertos e escurecidos com o vèo do affecto ou com a nuvem da payxão; se os cega o amor ou o odio, a inveja ou a lisonja, a vingança ou o interesse, a esperança ou o temor, como se póde entender a verdade da profecia por muyto clara que nella esteja, quando o primeyro intento he negalla, ou quando menos escurecela? As nuvens que Deos poem sobre a profecia, o tempo gasta e as desfaz; mas os vèos que os homens lanção sobre os proprios olhos, só elles os podem tirar, porque elles são os que querem ser cegos. Que profecias mais claras, que as da vinda de Christo ao mundo? E muyto mais claras ainda depois de manifestas e provadas com os mesmos effeytos. E com tudo, estas são as que mais obstinadamente nega a cegueyra Judaica, porque tem os olhos cubertos com aquelle antigo vèo de Moysês, como lhes lançou em rosto o grande Paulo Judeo, \& semente de Abraham, como elles da Tribu de Benjamim [...] Tirem o vèo de sobre os olhos e verão a luz das profecias. Ainda que a profecia seja candea acesa, como se ha de ver com os olhos cubertos? Tire-se o impedimento à luz e logo se verão a candea e mais o que ella alumea". Passagem que se pode comparar ao cap. IV da Synagoga.
} 
diplomata, foi um dos grandes homens de Estado de Portugal. Segundo Andrée Mansuy Diniz Silva, ao perceber as desordens causadas pelos descobrimentos das minas, Andreoni quis, através da Cultura e opulência do Brasil por suas drogas e minas, "dissipar as miragens do ouro" e mostrar aos senhores de engenho e aos plantadores de cana a sua importância na vida econômica de Portugal e lhes dar esperança de que seus méritos fossem reconhecidos (Diniz Silva 2001). Do mesmo modo, ao traduzir a Sinagoga, ele evoca as desordens, desta vez espirituais, que poderiam (de acordo com os conceitos da época) pôr em risco a paz do império. É justamente esta virtude da obra que chama a atenção do censor real, pois segundo este - utilizando-se do jogo barroco do duplo sentido, religioso e político, de fiel - os judeus se desenganando, "não terá V. Majestade Vassalos que não sejão fieis" (Pinamonti 1720, censura de Pedro Álvares).

\section{Referências Bibliográficas}

ALDEN, Dauril. The making of an enterprise, the Society of Jesus in Portugal, it's Empire and beyond: 1540-1750. Stanford, Stanford University Press, 1996.

BARBOSA MACHADO, Diogo. Bibliotheca Lusitana Historica Critica e Chronologica [...], (3 vol.) (4 ed., em Cd-Rom), Lisboa, Comissão Nacional para as Comemorações dos Descobrimentos Portugueses, s.d. (1ª ed.: 1741-1759).

COLLENBERG, Wipertus H. Rudt de. "Le baptême des juifs à Rome de 1614 à 1798 selon les registres de la 'casa dei catecumeni'”. In: Archivum Historice Pontifica. vol. XXIV (1986), p. 91-95.

DINES, Alberto. Vínculos de Fogo, Antônio José da Silva, o Judeu, e outras histórias da Inquisição em Portugal e no Brasil. São Paulo, Companhia das Letras, 1992.

DINIZ SILVA, Andrée Mansuy. introdução a André João ANTONIL, Cultura e opulência do Brasil por suas drogas e minas, Lisboa, CNCDP, 2001.

DURAZZO, G. F. Raccolta delle virtù del P. Gian Pietro Pinamonti Missionario della Compagnia di Giesù [...], Roma, Antonio de' Rossi, 1709.

FALBEL, Nachman. "Um argumento polêmico em Vicente da Costa Matos". Nachman Falbel, Alberto Dines e Avraham Milgram (org.). Em nome da Fé, estudos in memoriam de Elias Lipiner. São Paulo, Perspectiva, 1999, p. 91-113. 
GLASER, Edward. "Invitation to Intolerance: A Study of the Portuguese Sermons Preached at Auto-da-fé". In: Hebrew Union College Annual, XXVII (1956), p.327-385.

JESUS, Ruperto de. Sermam do glorioso S. Pedro Martyr, [...] mandado imprimir pelos Familiares do Santo Officio da Cidade da Bahia. Na occasião em que celebràrão a sua primeyra Festa [...] na era de 1697. Lisboa, na Officina de Antonio Pedroso Galrão, 1700.

LEITE, Antônio Serafim. História da Companhia de Jesus no Brasil. Rio de Janeiro, Imprensa Nacional, 1938-1950 (10 vol.).

MATTOS, Vicente da Costa. Breve discurso contra a heretica perfidia do Iudaismo continuada nos presentes apostatas de nossa santa Fé, com o que conuem a expulsão dos delinquentes nella dos Reynos de sua Magestade, com suas molheres \& filhos [...]. Lisboa, Pedro Craesbeek, 1622.

NOVINSKY, Anita. "Reflexões sobre o anti-semitismo (Portugal séculos XVI-XX)". In: Congresso Internacional Portugal no século XVIII de D. João V à Revolução Francesa. Sociedade Portuguesa de Estudos do Século XVIII/Universitária Editora, Lisboa, 1991, p. 450-461.

NOVINSKY, Anita. Inquisição, Rol dos Culpados: Fontes para a História do Brasil/séc. XVIII. Rio de Janeiro, Expressão e Cultura, 1992.

ORFALI, Moisés. “The Portuguese Edition (1565) of Hieronymus de Sancta Fide's Contra Iudaeos". Ora Limor e Guy Stroumsa (ed.). In: Sonderdruck aus Contra Iudaeos, Ancient and Medieval Polemics between Christians and Jews. Tübingen, J. C. B. Mohr (Paul Siebeck), s.d., p. 239-256.

PINAMONTI, Giovanni Pietro. La Sinagoga disinganata, overo via facile à mostrare a qualunque Ebrèo la falsità della sua setta. E la verità della Legge Cristiana. Opera non meno utile à gli Adoratori di Cristo, che à suoi Nemici. Roma, Dom. Ant. Ercole, 1694.

PINAMONTI, Giovanni Pietro. Opere del Padre Gio: Pietro Pinamonti della Compagnia di Gesu, con un breve ragguaglio della sua vita. Parma, Paolo Monti, 1706.

PINAMONTI, Giovanni Pietro. Synagoga dezenganada, obra do Padre Joaõ Pedro Pinamonti da Companhia de JESU, Traduzida da Lingua Italiana em a Portugueza, por hum Religiozo da mesma Companhia, offerecida aos Senhores Inquizidores do Reyno, e Conquistas de Portugal, E impressa por mandado do Illustrissimo Senhor D. Sebastiaõ Monteyro da Vide, Arcebispo da Bahia, do Conselho de Sua Magestade, \&c. Lisboa, Officina da Musica, 1720.

PINAMONTI, Giovanni Pietro. La sinagoga disinganata. Ossia via facile a mostrare a qualunque Ebreo o altro incredulo la falsità della sua setta, e la verità della Legge Cristiana. Opera composta dal Padre Gio : Pietro Pinamonti D. C. D. G. Nápoles, Prem. Stab. Cav. G. M. Priore, Via Pallonetto S. Chiara, 22, 1911. 
RÉVAH, Israël-Salvator. "O Diálogo Evangélico sobre os artigos da Fé contra o Talmud dos judeus de João de Barros". In: Charles Amiel (pub.). Etudes Portugaises, Paris, Centre Calouste Gulbenkian, 1975, p. 51-97.

RIBEIRO DOS SANTOS, António. "Ensayo de huma Bibliotheca Lusitana Anti-Rabbinica, ou Memorial dos Escritores Portuguezes que escrevêrão de Controversia Anti-judaica”. In: Memórias da Literatura Portugueza, Academia Real das Ciencias de Lisboa, t. VII (1806), p. 308-377.

SILVA, Innocêncio F. da. Diccionario bibliographico Portuguez, estudos de applicáveis a Portugal e ao Brasil. Lisboa, Imprensa Nacional, 1858 (7 vol.).

SOMMERVOGEL, Carlos. Bibliothèque de la Compagnie de Jésus. Bruxelas/Paris, la Province de Belgique (S.J.), 1890-1909 (11 vol.+1).

STUCZYNSKI, Claude Bernard. "Subsídios para um estudo de dois modelos paralelos de 'catequização' dos judeus em Portugal”. Nachman Falbel, Alberto Dines e Avraham Milgram (org.). Em nome da Fé, estudos in memoriam de Elias Lipiner. São Paulo, Perspectiva, 1999, p. 173-201.

TORREJONCILLO, Francisco. Centinella contra judeos, posta em a Torre da Igreja de Deos [...]. Lisboa, João Galrão, 1684.

VARNHAGEN, Francisco Adolfo de. "Excerptos de várias listas de condemnados pela Inquisição de Lisboa desde o anno de 1711 ao de 1767, comprehendendo só os Brazileiros, ou Colonos estabelecidos no Brazil”. In: Revista do Instituto Histórico e Geográfico Brasileiro, $\mathrm{n}^{\circ} 25$ (abril 1845), p. 54-87.

VIEIRA, Antônio. Historia do Futuro. Livro anteprimeyro prolegomeno a toda a historia do Futuro, em que se declara o fim, \& se provã̃ os fundamentos della. Materia, Verdade, \& Utilidades da Historia do Futuro. Lisboa, Antonio Pedrozo Galram, 1718. 